\title{
Comparison of the Automated Fluorescent Immunoassay System With Roche Elecsys and Beckman Coulter Access 2 Assays for Anti-Müllerian Hormone Measurement
}

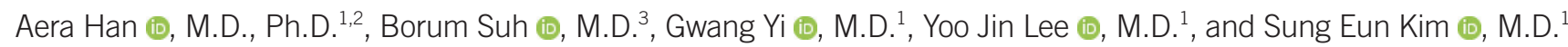 \\ ${ }^{1}$ I-dream Clinic, Department of Obstetrics and Gynecology, MizMedi Hospital, Seoul, Korea; ${ }^{2}$ Deagu Cha Fertility Center, CHA University, Daegu, Korea; \\ ${ }^{3}$ Department of Laboratory Medicine, MizMedi Hospital, Seoul, Korea
}

Background: Since 2017, automated assays have been used in most clinical laboratories for anti-Müllerian hormone (AMH) level measurement. We evaluated the analytical performance of the newly developed automated fluorescent immunoassay system (AFIAS) AMH assay (Boditech Med, Gangwon-do, Korea) in comparison with the Roche Elecsys and Beckman Coulter Access 2 AMH assays.

Methods: Analytical performance of the AFIAS AMH assay was assessed in terms of linearity, repeatability, and within-laboratory precision (CV\%) using human recombinant AMH samples according to the Clinical and Laboratory Standards Institute (CLSI) guidelines EP05 and EP06. Using 293 serum samples collected from an infertility clinic, the AMH levels were compared across AFIAS, Elecsys, and Access $2 \mathrm{AMH}$ assays according to the CLSI EP09 guidelines.

Results: The AFIAS AMH assay results were linear across the measurement range of $0.420-72.386 \mathrm{pmol} / \mathrm{L} \mathrm{AMH}$, with repeatability of $6.341 \%$. CV\% of the AFIAS AMH assay for three levels of control, 1.786, 7.143, and $56.857 \mathrm{pmol} / \mathrm{L}$, were $5.801 \%, 5.714 \%$, and $6.228 \%$, respectively. The results of the three $\mathrm{AMH}$ assays showed strong correlation: AFIAS and Elecsys [slope, 1.055 (95\% confidence interval (Cl), 1.022-1.088) and Spearman's rho, $0.978(95 \% \mathrm{Cl}, 0.973-0.983)$ ], Elecsys and Access 2 [slope, $0.813(95 \% \mathrm{Cl}$, 0.791-0.834) and Spearman's rho, 0.986 (95\% Cl, 0.983-0.989)], and AFIAS and Access 2 [slope, 0.836 (95\% Cl, 0.821-0.853) and Spearman's rho, $0.984(95 \%$ Cl, 0.9800.988)].

Conclusions: The AFIAS AMH assay may be an alternative to the Roche Elecsys and Beckman Coulter Access 2 AMH assays.

Key Words: Anti-Müllerian hormone, Automated fluorescent immunoassay system $\mathrm{AMH}$ assay, Performance, Comparison
Received: July 4, 2020

Revision received: November 24, 2020

Accepted: July 21, 2021

\section{Corresponding author:}

Aera Han, M.D., Ph.D.

Daegu Cha Feritility Center, CHA University, 24 Duryugongwon-ro, Nam-gu, Daegu 42469, Korea

Tel: +82-53-656-4200

Fax: +82-53-656-0198

E-mail: sonagyhan@gmail.com

\section{INTRODUCTION}

Anti-Müllerian hormone (AMH) is a homodimeric glycoprotein linked by disulfide bonds with a molecular weight of $140 \mathrm{kDa}$ and belongs to the transforming growth factor- $\beta$ (TGF- $\beta$ ) superfamily. AMH production by embryonic Sertoli cells induces Müllerian ducts; thus, this hormone plays a vital role in male sex differentiation [1]. In women, granulosa cells of the small antral 
and pre-antral follicles produce $\mathrm{AMH}$, and the $\mathrm{AMH}$ expression pattern is suggested to correlate with the number of early growing follicles [2]. Therefore, $\mathrm{AMH}$ in women may serve as an indicator of the ovarian reserve and a predictor of the ovarian response to hyperstimulation [2-8].

Since the development and market introduction of ELISAs by Diagnostic Systems Lab (DSL, Webster, TX, USA) and Immunotech (IOT, Marseilles, France) two decades ago, several $\mathrm{AMH}$ immunoassays, including automated assays, have been developed [9-12]. The Elecsys AMH assay (Roche Diagnostics, Basel, Switzerland) and the Access $2 \mathrm{AMH}$ assay (Beckman Coulter, Brea, CA, USA) are widely used automated assays. Owing to their large assay capacity, they are suitable for clinical laboratories [12]. However, small in vitro fertilization (IVF) laboratories and clinics require automated assays combined with point-ofcare (POC) instruments for performing small numbers of assays.

Recently, Boditech Med (Chuncheon, Korea) developed an automated fluorescent immunoassay system (AFIAS) AMH assay, which is an automated one-step immunoassay with timeresolved fluorescence detection using an all-in-one cartridge consisting of all factory-calibrated reagents. The AFIAS AMH assay uses only $100 \mu \mathrm{L}$ of blood and takes only 3-15 minutes to deliver the result. We evaluated the analytical performance of the AFIAS AMH assay in comparison with that of the Elecsys and Access $2 \mathrm{AMH}$ assays.

\section{MATERIALS AND METHODS}

\section{Samples}

Serum samples were collected prospectively at the infertility clinic of MizMedi Hospital, Seoul, Korea, between December 6, 2018 and July 20, 2019, with approval of the Ethics Committee on Human Subjects of MizMedi Hospital (MMIRB2018-10). In total, 332 participants (age range, 19-49 years) were enrolled in this study and provided informed consent. Thirty-nine participants were excluded from the analyses for the following reasons: nine participants withdrew consent, four were not Korean, and
26 had serum AMH levels below or above the measurement range of the AFIAS AMH assay. Collected serum samples from the remaining 293 women (mean age, 34.27 \pm 5.13 years) were aliquoted into two tubes for standard laboratory AMH level measurement. For assay comparison, samples were stored in the freezer $\left(-20^{\circ} \mathrm{C}\right)$ until $\mathrm{AMH}$ level measurement. Sample stability was assessed by analyzing the differences in $\mathrm{AMH}$ levels between fresh serum samples (day 0) and frozen/thawed samples using a reference instrument (Beckman Coulter Access 2), according to the European Medicines Agency (EMA) guidelines [13].

\section{Measurement}

We followed the CLSI EP06 guidelines to measure the linearity of the AFIAS AMH assay [14]. We prepared a series of human recombinant $\mathrm{AMH}$ samples with known $\mathrm{AMH}$ levels (Boditech Med), ranging from a low (near the lower limit of quantification) to a high level (close to the upper limit of quantification). We analyzed each sample in 10 replicates and generated linear and non-linear regression equations [14].

Repeatability and within-laboratory precision of the AFIAS AMH

Table 1. Summary of linear and non-linear regression analyses of the AFIAS AMH assay results

\begin{tabular}{|c|c|c|c|c|c|}
\hline Model & Y-intercept & $x$ & $x^{2}$ & $x^{3}$ & $\begin{array}{c}\text { Standard } \\
\text { error }\end{array}$ \\
\hline \multicolumn{6}{|l|}{ Linear } \\
\hline Coefficient & -0.004 & 1.013 & NA & NA & 0.425 \\
\hline$P$ & 0.971 & $<0.001$ & NA & NA & \\
\hline \multicolumn{6}{|c|}{ Polynomial 2nd order } \\
\hline Coefficient & -0.062 & 1.055 & -0.004 & NA & 0.427 \\
\hline$P$ & 0.629 & $<0.001$ & 0.461 & NA & \\
\hline \multicolumn{6}{|c|}{ Polynomial 3rd order } \\
\hline Coefficient & -0.044 & 1.022 & 0.005 & -0.001 & 0.431 \\
\hline$P$ & 0.752 & $<0.001$ & 0.879 & 0.779 & \\
\hline
\end{tabular}

Abbreviations: AFIAS, automated fluorescent immunoassay system; $\mathrm{AMH}$ anti-Müllerian hormone; NA, not available.

Table 2. Repeatability and within-laboratory precision of the AFIAS AMH assay

\begin{tabular}{|c|c|c|c|c|c|c|c|}
\hline \multirow{2}{*}{ Control AMH level } & \multirow{2}{*}{$\begin{array}{c}\text { Control target } \\
(\mathrm{pmol} / \mathrm{L})\end{array}$} & \multirow{2}{*}{$\begin{array}{l}\text { Range of control } \\
(\mathrm{pmol} / \mathrm{L})\end{array}$} & \multirow{2}{*}{$\begin{array}{l}\text { Measured mean } \\
\quad(\mathrm{pmol} / \mathrm{L})\end{array}$} & \multicolumn{2}{|c|}{ Repeatability } & \multicolumn{2}{|c|}{ Within-laboratory precision } \\
\hline & & & & $\mathrm{SD}(\mathrm{pmol} / \mathrm{L})$ & CV (\%) & $\mathrm{SD}(\mathrm{pmol} / \mathrm{L})$ & CV (\%) \\
\hline Low & 1.786 & $1.434-2.151$ & 1.793 & 0.101 & 5.642 & 0.104 & 5.801 \\
\hline Medium & 7.143 & $5.704-8.556$ & 7.130 & 0.403 & 5.659 & 0.407 & 5.714 \\
\hline High & 56.857 & $45.513-68.269$ & 56.891 & 3.190 & 5.607 & 3.543 & 6.228 \\
\hline
\end{tabular}

Abbreviations: AFIAS, automated fluorescent immunoassay system; AMH, anti-Müllerian hormone; SD, standard deviation; CV, coefficient variation. 
assay were calculated using three control human recombinant AMH samples with known AMH levels according to a modified protocol presented in the CLSI EP05 guidelines: 20 days, two runs daily, and six replicates per run [15].

\section{Statistical analysis}

The results obtained using the AFIAS, Elecsys, and Access 2 AMH assays were compared using Passing-Bablok regression analysis and Bland-Altman methods, according to the CLSI EPO9 guidelines [16]. Statistical analyses for Passing-Bablok regression, Bland-Altman plot, and Spearman's correlation were conducted using MedCalc software (version 19.2.0, MedCalc Software bvba, Ostend, Belgium) and R software (R Core Team 2014, Vienna, Austria). A $P$ value $<0.05$ was considered statistically significant.

\section{RESULTS}

Linear results were obtained across the measurement range of $0.420-72.386 \mathrm{pmol} / \mathrm{L}$, with repeatability of $6.341 \%$ for all samples (Table 1). The repeatability and within-laboratory precision of the AFIAS AMH assay were $5.607 \%-5.659 \%$ and $5.714 \%-$ $6.228 \%$, respectively, which were within the ranges reported by the manufacturer (Table 2).

Age-specific AMH levels in the 10th, 50th, and 90th percen-

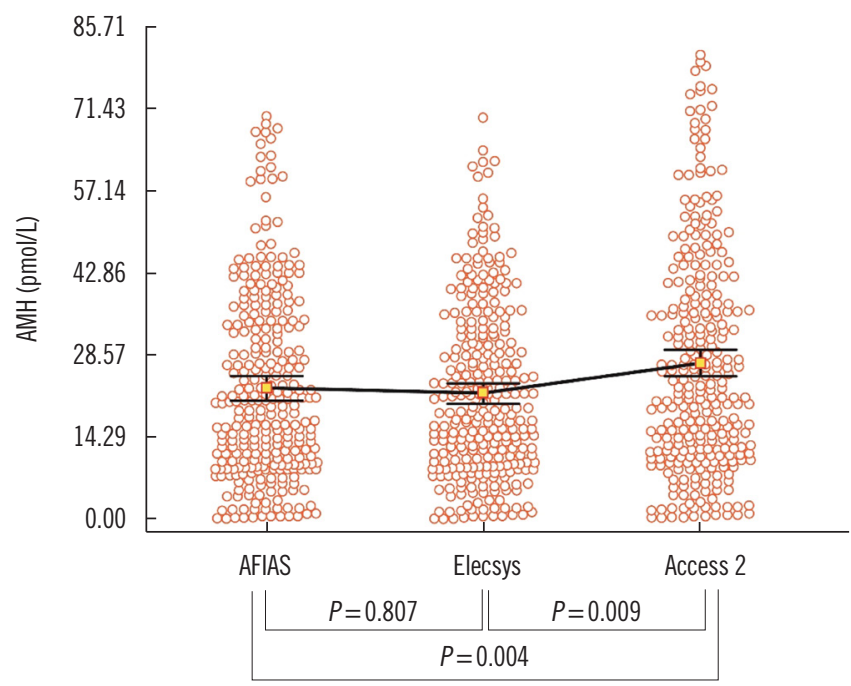

Fig. 1. Distribution of AMH levels measured using the AFIAS, Elecsys, and Access $2 \mathrm{AMH}$ assays. Squares and bars represent the median of measured data and $95 \% \mathrm{Cl}$.

Abbreviations: $\mathrm{AMH}$, anti-Müllerian hormone; AFIAS automated fluorescent immunoassay system; $\mathrm{Cl}$, confidence interval.

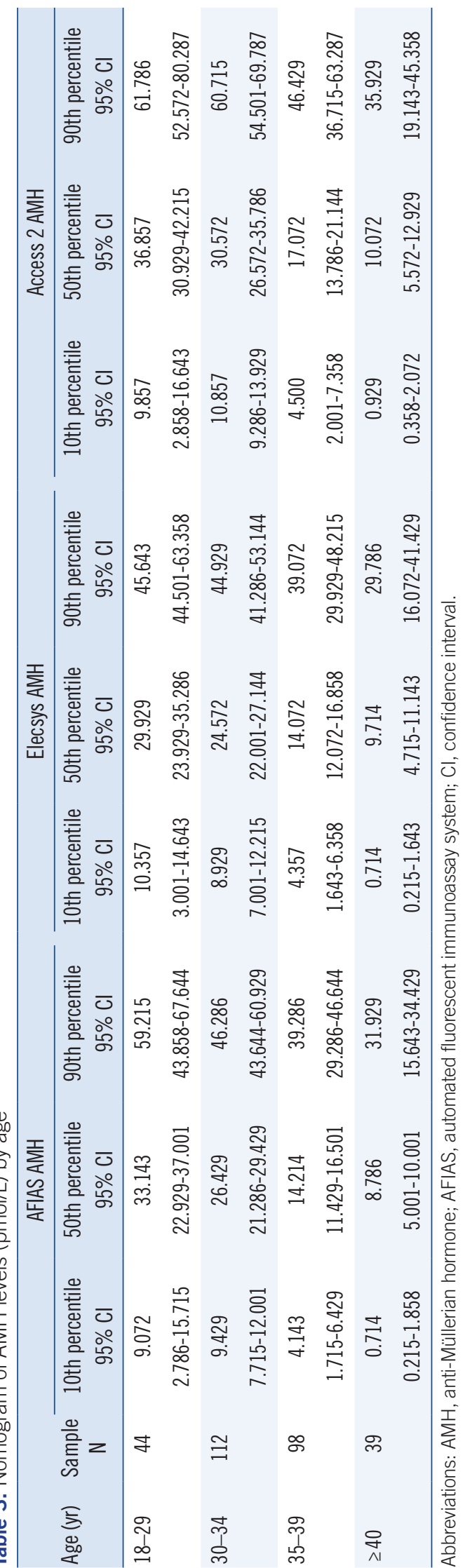



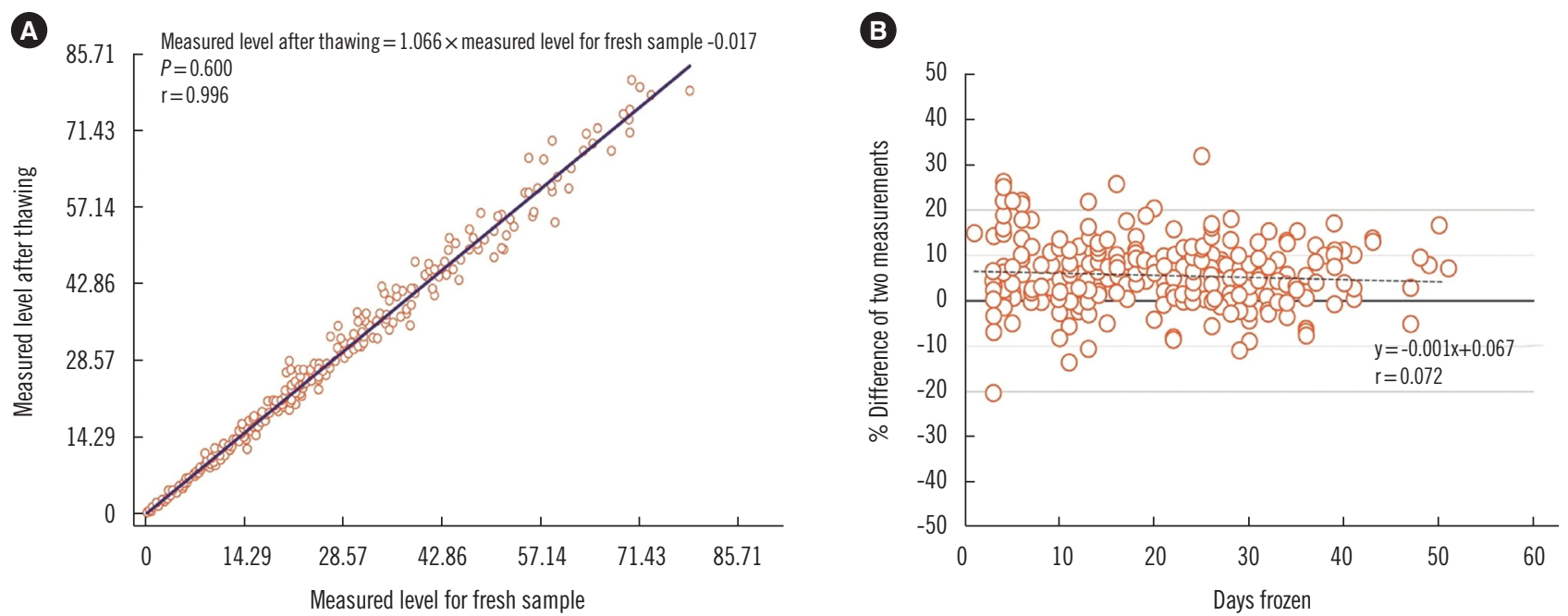

Fig. 2. Correlation between two measurements of fresh and frozen-thawed samples. (A) Scatter plots with regression line of two measurements. (B) Percent difference between two measurements. Thick and thin solid lines represent $0 \%, \pm 10 \%$, and $\pm 20 \%$ differences, respectively. Dotted line represents the regression line of the mean difference between the two measurements.

tiles, with 95\% confidence intervals (Cls) calculated from the measurements obtained with each assay are shown in Table 3. The AMH levels obtained using the AFIAS and Elecsys AMH assays were similar $(P=0.807)$, whereas the Access $2 \mathrm{AMH}$ assay yielded higher values $(P=0.009)$ (Fig. 1$)$.

We redetermined the AMH level in each sample using the Access $2 \mathrm{AMH}$ assay to ensure sample stability under storage at $-20^{\circ} \mathrm{C}$. The measured levels for the thawed samples tended to be slightly higher (measured level after thawing $=1.066 \times$ measured level for fresh sample - 0.017, Spearman's correlation coefficient $r=0.996$ ), but the differences were acceptable ( $96 \%$ of the samples showed a difference under $20 \%$, while $76 \%$ samples showed a difference under 10\%) (Fig. 2).

Strong correlations with no significant differences were found among the results of the three AMH assays (Fig. 3): The slope and Spearman's rho were $1.055(95 \% \mathrm{Cl}, 1.022-1.088)$ and 0.978 (95\% Cl, 0.973-0.983) between AFIAS and Elecsys, 0.813 (95\% Cl, 0.791-0.834) and $0.986(95 \% \mathrm{Cl}, 0.983-0.989)$ between Elecsys and Access 2, and 0.836 (95\% Cl, 0.821-0.853) and 0.984 (95\% Cl, 0.980-0.988) between AFIAS and Access 2 , respectively. The Bland-Altman plot showed no significant systemic error across the AMH level measurement range among assays.

\section{DISCUSSION}

We found competent repeatability, within-laboratory precision, and adequate linearity of the recently developed AFIAS AMH assay with comparable measurement values to those of the Elecsys and Access $2 \mathrm{AMH}$ automated assays.

$\mathrm{AMH}$ level measurement is a popular approach to assess the ovarian reserve and identify extreme responses before ovarian stimulation in IVF treatment, because the AMH level highly correlates with the antral follicle count $[17,18]$. The usual starting point of ovarian stimulation for IVF is menstrual cycle day (MCD) 2 or 3 . The starting dose of gonadotropin in ovarian stimulation is adjusted according to the ovarian reserve, and hormonal levels are checked in the early follicular phase (MCD 2-3). Determination of the levels of $\mathrm{AMH}$ and other hormones on the starting day of ovarian stimulation would greatly assist timely adjustment of gonadotropin dose. The impact of the proverbial biological clock, the so-called "ovarian age," on egg quality and quantity is also a concern in relatively older ( $>40$ years) patients in IVF clinics, who do not want to delay ovarian stimulation. Hence, reducing the laboratory turn-around time of assays for $\mathrm{AMH}$ and other hormones is preferable.

In small- to medium-sized IVF clinics, blood samples are usually sent out to reference laboratories. Outsourcing of hormonal assays not only takes more time but may also affect the quality of the laboratory results. AMH level measurement with a short turn-around time would significantly contribute to patient satisfaction. To our knowledge, the AFIAS AMH assay is the only POC automated AMH assay currently available, offering an affordable on-site laboratory assay for small- to medium-sized IVF clinics with reduced laboratory assay capacity.

This study is the first to compare three automated AMH as- 
Han A, et al.

Performance evaluation of AFIAS AMH assay
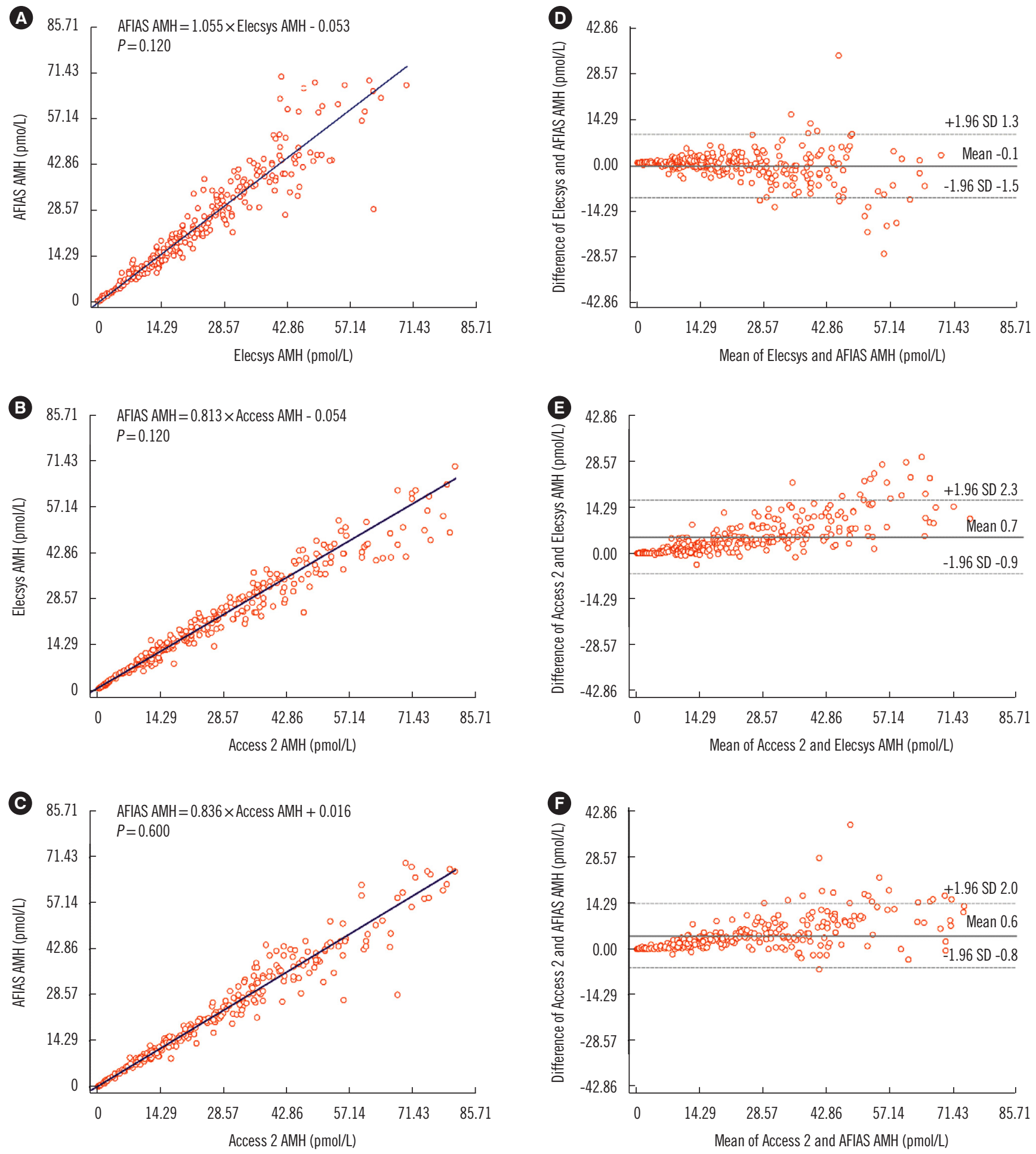

Fig. 3. Correlation analyses of the three AMH assays. (A), (B), and (C) show Passing-Bablok regression plots of the three AMH assays. Solid lines represent the regression of two measurements. (D), (E), and (F) show Bland-Altman plots of the appropriate comparison between the $\mathrm{AMH}$ assays.

Abbreviations: AMH, anti-Müllerian hormone; AFIAS, automated fluorescent immunoassay system. 
says (AFIAS, Elecsys, and Access 2) using serum samples from patients. As the AFIAS AMH assay results showed strong correlations with the results of the other two assays (Fig. 3), it could serve as a convenient alternative. The distributions of $\mathrm{AMH}$ levels measured using the AFIAS and Elecsys AMH assays were similar, whereas the Access $2 \mathrm{AMH}$ assay showed a slightly wider distribution (Fig. 1). Similar distribution patterns among assays were found for age-specific AMH levels (Table 3). This indicates that assay-specific AMH levels need to be carefully interpreted. Since AMH level measurement has not yet been standardized $[17,18]$, it is preferable to use the same assay when testing $\mathrm{AMH}$ level serially for the same patient.

We only considered age and AMH level for each participant and did not analyze correlations of $\mathrm{AMH}$ levels with clinical profiles. Therefore, we cannot offer any practical suggestion regarding the most suitable AMH level for infertility treatment. Further, serum samples were obtained only from participants who had registered for infertility treatment. Therefore, our data do not indicate age-specific AMH levels in the general population of Korean women.

Despite these limitations, we showed the competent repeatability and within-laboratory precision and adequate linearity of AFIAS AMH assay, and its performance was satisfactory compared with the widely used Elecsys Access 2 AMH assays. Therefore, the AFIAS AMH assay can be an alternative to existing immunoassays.

\section{ACKNOWLEDGEMENTS}

We thank Boditech Med for providing the AFIAS AMH assay kit.

\section{AUTHOR CONTRIBUTIONS}

Han A designed the study, collected data, and wrote and revised the manuscript. Suh B supervised the laboratory work and proofread the manuscript. Lee $\mathrm{G}$ designed the study and collected the samples. Lee $Y$ and Kim S collected samples. All authors read and approved the final manuscript.

\section{CONFLICTS OF INTEREST}

None declared.

\section{RESEARCH FUNDING}

This work is supported by MizMedi Internal research fund.

\section{ORCID}

Aera Han

Borum Suh

Gwang Yi

Yoo Jin Lee

Sung Eun Kim

https://orcid.org/0000-0002-5432-548X https://orcid.org/0000-0002-9224-6950 https://orcid.org/0000-0002-0092-5885 https://orcid.org/0000-0002-6195-5375 https://orcid.org/0000-0002-3620-8212

\section{REFERENCES}

1. Carmina E, Stanczyk F, et al. Evaluation of hormonal status. In: Strauss JF and Barbieri RL, eds. Yen and Jaffe's reproductive endocrinology. 8th ed. Amsterdam: Elsevier, 2018: 900-1.

2. Lie Fong S, Visser JA, Welt CK, de Rijke YB, Eijkemans MJ, Broekmans FJ, et al. Serum anti-Müllerian hormone levels in healthy females: a nomogram ranging from infancy to adulthood. J Clin Endocrinol Metab 2012;97:4650-5.

3. de Vet A, Laven JS, de Jong FH, Themmen AP, Fauser BC. Antimüllerian hormone serum levels: a putative marker for ovarian aging. Fertil Steril 2002;77:357-62.

4. van Rooij IA, Broekmans FJ, te Velde ER, Fauser BC, Bancsi LF, de Jong $\mathrm{FH}$, et al. Serum anti-Müllerian hormone levels: a novel measure of ovarian reserve. Hum Reprod 2002;17:3065-71.

5. Lie Fong S, Baart EB, Martini E, Schipper I, Visser JA, Themmen AP, et al. Anti-Müllerian hormone: a marker for oocyte quantity, oocyte quality and embryo quality? Reprod Biomed Online 2008;16:664-70.

6. Fanchin R, Schonäuer LM, Righini C, Guibourdenche J, Frydman R, Taieb J. Serum anti-Mullerian hormone is more strongly related to ovarian follicular status than serum inhibin B, estradiol, FSH and LH on day 3. Hum Reprod 2003;18:323-7.

7. van Rooij IA, Broekmans FJ, Scheffer GJ, Looman CW, Habbema JD, de Jong $\mathrm{FH}$, et al. Serum antimullerian hormone levels best reflect the reproductive decline with age in normal women with proven fertility: a longitudinal study. Fertil Steril 2005;83:979-87.

8. Broer SL, Dólleman M, Opmeer BC, Fauser BC, Mol BW, Broekmans FJ. AMH and AFC as predictors of excessive response in controlled ovarian hyperstimulation: a meta-analysis. Hum Reprod Update 2011;17: 46-54.

9. Kumar A, Kalra B, Patel A, McDavid L, Roudebush WE. Development of a second generation anti-Müllerian hormone (AMH) ELISA. J Immunol Methods 2010;362:51-9.

10. Gassner D and Jung R. First fully automated immunoassay for anti-Müllerian hormone. Clin Chem Lab Med 2014;52:1143-52.

11. Pearson K, Long M, Prasad J, Wu YY, Bonifacio M. Assessment of the access $\mathrm{AMH}$ assay as an automated, high-performance replacement for the AMH generation II manual ELISA. Reprod Biol Endocrinol 2016; 14:8.

12. Pastuszek E, Lukaszuk A, Kunicki M, Mockun J, Kloss G, Malinowska I, et al. New AMH assay allows rapid point of care measurements of ovarian reserve. Gynecol Endocrinol 2017;33:638-43.

13. European Medicines Agency. Guideline on bioanalytical method validation. EMEA/CHMP/EWP/192217/2009 Rev. 1 Corr. 2**. https://www. ema.europa.eu/en/documents/scientific-guideline/guideline-bioanalytical-method-validation_en.pdf (Updated on 21July 2011).

14. CLSI. Evaluation of the linearity of quantitative measurement procedures: A statistical approach; Approved guideline. 2nd ed. EP06. Wayne, PA Clinical and Laboratory Standards Institute. 2020. 
Han A, et al.

Performance evaluation of AFIAS AMH assay

15. CLSI. Evaluation of precision of quantitative measurement procedures; Approved guideline. 3rd ed. EP05. Wayne, PA: Clinical and Laboratory Standards Institute. 2014.

16. CLSI. Measurement procedure comparison and bias estimation using patient samples; Approved guideline. 3rd ed. EP09. Wayne, PA: Clinical and Laboratory Standards Institute. 2018.
17. Dewailly D, Andersen CY, Balen A, Broekmans F, Dilaver N, Fanchin R, et al. The physiology and clinical utility of anti-Müllerian hormone in women. Hum Reprod Update 2014;20:370-85.

18. Nelson SM, Pastuszek E, Kloss G, Malinowska I, Liss J, Lukaszuk A, et al. Two new automated, compared with two enzyme-linked immunosorbent, antimüllerian hormone assays. Fertil Steril 2015;104:1016-21.e6. 